\title{
Cannabis Transactions and Law Reform
}

\section{Chris Wilkins}

$\mathrm{T}$ The New Zealand government recently announced that a Parliamentary Select Committee would investigate the most effective public health strategies to reduce the harm of cannabis, including its legal status. Public hearings of submissions began on 30 May this year.

Those in favour of the legalisation of cannabis in New Zealand have pointed out that if cannabis were legalised buyers and sellers of the drug would have full access to the legal and consumer protections currently enjoyed by all other consumers (see Drug Policy Forum Trust, 1997 and 1998; www.norml.org.nz; www.alcp.org.nz). Under drug prohibition, drug users and drug dealers cannot call on the police and courts to enforce the terms of transactions, and are unlikely to report incidents of victimisation to the police for fear of prosecution. (Barnett, 1987; Kleiman, 1992; Miron and Zwiebel, 1995).

The reliability of black market cannabis transactions has a number of implications for cannabis law reform. It impacts on how socially costly the present policy of prohibition is, and hence, in part, the extent of the case for cannabis law reform (Field and Casswell, 2000). If large numbers of people are physically or economically harmed when purchasing cannabis from the black market, this consequence, along with any other negative consequences of prohibition, should be weighed up against the positive benefits of maintaining prohibition.

The issue of transactional reliability of the black market also impacts on the extent of the social benefits that can be expected if cannabis were legalised. A very unreliable and violent black market would suggest there might be significant social benefits from the legalisation and regulation of the market. Alternatively, a relatively reliable and peaceful black market would suggest the social benefits from legalisation and regulation of the market may be small.

This paper investigates the reliability of black market cannabis transactions in New Zealand, and discusses the implications for cannabis law reform. It begins by using economic theory to develop a simple model of the reliability of illicit drug transactions. It then presents the findings of a survey of members of the Aotearoa Legalise Cannabis Party (ALCP) about the reliability of their cannabis transactions. The conclusion explores the implications of the model and survey have for cannabis law reform in New Zealand.

Chris Wilkins is a Research Fellow at the Alcohol \& Public Health Research Unit, Faculty of Medicine and Health Science, University of Auckland. 


\section{Reliability of Illicit Drug Transactions}

A problem shared by all exchange parties in illicit drug markets is they cannot call on the police and courts to enforce the terms of transactions (see Moore, 1977). The absence of third party enforcement means exchange parties are vulnerable to a range of opportunistic behaviour from exchange partners, including quality fraud (that is, misrepresenting low quality drugs as high quality drugs), product fraud (that is, selling phoney drugs), robbery, and assault.

Studies of stateless economic systems have identified a range of informal institutions that constrain opportunism and encourage reliable economic exchange when third party enforcement is absent (see Eggertsson, 1990; North, 1990). These include informal institutions such as dense social interaction, loyalty, credible physical retaliation, compensation and arbitration, social conditioning, personal reputation, conditional co-operation, and ongoing interaction. The description of illicit drug markets in the literature suggests the presence of many of these informal institutions will be the exception rather than the general rule of the market (see Moore, 1977; Michaels, 1987; Kleiman, 1992; Long, 1988; Reuter and Haaga, 1989).

The possibility that exchange in illicit drug markets might involve ongoing transactions between the same two exchange partners appears to offer a promising mechanism for encouraging reliable exchange. In many markets buyers often choose to repeatedly return to the same seller to take advantage of particular benefits unique to a seller, such as access to credit or convenient location. Repeat exchange relationships have been found to be common in illicit drug markets where drug dealers actively try to cultivate regular customers (Jacobs, 1999). Exchange parties in illicit drug markets have the added incentive to return to someone they have dealt with in the past because an exchange partner who has already completed a transaction is generally perceived to be less likely to be an undercover agent than a complete stranger.

Axelrod (1981 and 1990) has shown that the likelihood people will honour agreements in the absence of third party enforcement increases when they know they are going to meet the same person repeatedly in the future. Cheating at any one meeting will mean the mutual benefits from all future meetings will be lost forever. It will usually pay to honour a transaction in these circumstances because the one-off benefit of cheating will generally be less than the ongoing benefits of future exchange. In the context of illicit drug markets, a drug dealer may not cheat their customers because they know they will not return for future sales, and alternatively a drug user may not cheat their drug dealer because they know they would not be able to return for future purchases.

However, there is a serious objection to the application of the 'ongoing interaction' solution to illicit drug markets. A key assumption of the ongoing interaction solution is that all future interaction is with the same person. It is not possible to cheat on an agreement and then exit the relationship with the 'winnings'. This assumption does fit many real-world situations. For example, in politics, adversaries such as political parties, nation states, and long serving 
political representatives, know they are going to meet each other again and again in the future, and this knowledge often convinces them to cooperate in the present in the hope of extracting reciprocal behaviour in the future.

Market relationships, on the other hand, are often transient and ephemeral. The efficiency of the market comes from the ability of buyers to change sellers whenever superior terms are offered elsewhere or performance becomes unacceptable. The incentives to honour transactions with one exchange partner break down when it is possible to easily transact with others. A drug dealer could cheat one drug user and simply begin selling to a new drug user. Alternatively, a drug user could cheat their drug dealer and then simply find a new dealer to buy from. The benefits of cheating could be captured without losing any of the benefits of future trading.

This objection to the 'ongoing interaction' solution assumes exchange parties are able to costlessly and instantaneously switch exchange partners. Economists have come to realise there are real costs associated with arranging, specifying, and negotiating exchange successfully (Coase, 1960 and 1988). In some situations these 'transaction costs' are so high that they prevent any exchange from taking place (Demsetz, 1964). The transaction costs, or more specifically the search costs, of finding a replacement exchange partner will reduce the benefits of cheating a current exchange partner. If search costs in a market were high enough cheating would not pay in many instances. Drug dealers may not cheat drug users because it is costly to search for replacement buyers, and drug users may not drug dealers because it is costly to search for a replacement seller.

The literature on illicit drug markets suggests search costs are likely to be high in these markets compared to legal markets. Exchange partners are secretive and suspicious, and there are no market institutions to assist exchange parties with finding exchange partners, such as advertising, published information directories, or prominent store locations. Inquiries about contacts in the market must be selective and cautious to avoid the attention of the police and public embarrassment. The process of 'asking around' friends and social acquaintances about the identity of buyers and sellers is inexact and time consuming. Even when a drug dealer is identified, a new buyer may have to demonstrate their authenticity before the dealer will agree to sell drugs to them.

High search costs, in the context of an ongoing exchange relationship, may provide an explanation for why exchange parties in illicit drug markets choose to honour the terms of transactions even though there is no third party enforcement of transactions . Unfortunately, existing crime statistics and victimisation surveys in New Zealand are not detailed enough to identify incidents directly related to the purchase and sale of illicit drugs (see Wilkins, 1999). Gaining an understanding of the reliability of these transactions requires original data collection. With this purpose in mind, a small-scale survey of the reliability of cannabis transactions in New Zealand was undertaken. 


\section{A Survey of the Reliability of Cannabis Transactions in New Zealand}

Surveying buyers and sellers in illicit drug markets presents two central methodological challenges:

(1) overcoming participants' fear of prosecution and public embarrassment; and

(2) ensuring the safety of researchers employed to interview participants.

Previous studies of illicit drug markets (see Reuter, MacCoun and Murphy, 1990; Reuter and Haaga, 1989; Goldstein et al., 1989) have used specific institutional settings to overcome these barriers, such as probation meetings, prison populations, and neighbourhood field stations.

The ALCP was chosen as the institutional setting for this survey because it had a national membership who were likely to use and purchase cannabis, and it had an organisational structure to distribute a questionnaire by mail. The ALCP is a political party formed to create legislative pressure to liberalise cannabis laws in New Zealand.

A detailed description of the survey methodology can be found in Wilkins (1999). Briefly, a total of 1,313 questionnaires were posted out between 8 April and 13 May 1998. Questionnaires were mailed to eighteen different locations throughout the North and South Islands of New Zealand, including the four main centres and a host of smaller towns. The survey's response rate was 30 per cent $(n=357)$. This level of response was fairly good given that distribution and return of the questionnaire was by post, and there was no opportunity to follow up respondents. One hundred and thirty-four questionnaires were returned through the post marked 'return to sender'. It is likely many more questionnaires were sent to old addresses and were merely thrown out rather than sent back.

\section{Summary of Survey Results}

\section{Some characteristics of cannabis transactions}

A number of questions were asked about the characteristics of participant's cannabis transactions, including frequency of purchase, number of years of purchase, and the amount spent per transaction.

Many buyers in the ALCP sample purchased cannabis fairly frequently. Over half of the buyers (59\%) purchased cannabis once a week or more often.

Many buyers had been purchasing cannabis for a number of years. Just over two-thirds of buyers ( 69 per cent) had been buying cannabis for more than 5 years, and nearly half ( 43 per cent) had been buying cannabis for more than 10 years.

The amount spent on cannabis per transaction clustered around common units of cannabis sale in New Zealand (see National Drug Intelligence Bureau, 2000). Many buyers (47 per cent) spent $\$ 25$ or less per transaction, and most buyers (60 per cent) spent under $\$ 50$ (common prices for a bag of cannabis). Some buyers 
(22 per cent) spent $\$ 200-\$ 500$ per transaction, (the common price for an ounce of cannabis).

Number of times buyers were cheated ever

Buyers were asked to write how many times they had ever suffered from quality fraud, product fraud, robbery, and assault while purchasing cannabis in New Zealand.

Table 1 presents the percentage of buyers who had never experienced a type of cheating, and the percentage of buyers who experienced a type of cheating less than three times ever. The categories presented in the table are not mutually exclusive.

Table 1: Buyers and Cheating Frequency

\begin{tabular}{lcc}
\hline Type of Cheating & Never & Less than 3 Times \\
\hline Assault & 96 & 99 \\
Robbery & 91 & 97 \\
Product Fraud & 79 & 93 \\
Quality Fraud & 19 & 35 \\
\hline
\end{tabular}

The majority of buyers had never been assaulted ( 96 per cent) or robbed (91 per cent). Most buyers had never suffered from product fraud (79 per cent). In contrast, only 19 per cent of buyers had never suffered from quality fraud.

The majority of buyers had experienced product fraud ( 93 per cent), robbery ( 97 per cent), and assault ( 99 per cent) less than 3 times ever. Only 35 per cent of buyers experienced quality fraud less than three times ever. Thirty-seven percent of buyers suffered from quality fraud more than 10 times, and 27 per cent suffered from it more than 20 times.

\section{Level of cheating}

The number of transactions completed by each buyer was used to calculate the average incidence of cheating experienced per 100 transactions. Determining the total number of transactions completed by each buyer was problematic. In situations where a buyer had been purchasing cannabis for many years, and/or purchased cannabis quite frequently, they were unlikely to be able to recall the total number of transactions they had completed with any kind of accuracy. Consequently, rather than ask respondents directly to estimate the number of transactions they had completed, respondents were asked how many years they had been purchasing cannabis, and how frequently they had purchased cannabis in the previous year. These two questions were then combined to calculate the approximate number of transactions completed by each buyer. 
The number of transactions completed by each buyer ranged widely. Three quarters of buyers (77 per cent) had completed over 100 transactions, just over half ( 53 per cent) had completed over 300 transactions, and a quarter ( 26 per cent) had completed over 1000 transactions.

Table 2 presents the percentage of buyers who experienced three levels of cheating per 100 transactions: less than 0.1 times per 100 transactions; less than one time per 100 transactions; and greater than five times per 100 transactions. These categories were chosen to illustrate three distinct levels of cheating. The lower category represents a situation where a buyer experiences an incident of cheating less than one time in 1000 transactions. The middle category represents a situation where a buyer experiences cheating less than one time in 100 transactions. The last category represents a situation where a buyer experiences cheating more than five times every 100 transactions. The first two categories of the table are not mutually exclusive.

Nearly all the buyers experienced assault (98 per cent) and robbery (94 per cent) less than 0.1 times per 100 transactions. No one experienced assault more than 5 times per 100 transactions. Eighty-five percent of buyers experienced product fraud less than 0.1 times per 100 transactions. Only 21 per cent of buyers experienced quality fraud less than 0.1 times per 100 transactions.

Forty-one percent of buyers experienced quality fraud more than 5 times per 100 transactions and 11 per cent experienced quality fraud more than 40 times per 100 transactions.

\section{Table 2: Percentage of Buyers Who Experienced Three Levels of Cheating Per 100 Transactions}

\begin{tabular}{lccc}
\hline & \multicolumn{3}{c}{ Number times cheated per 100 transactions } \\
& Less than 0.1 & Less than 1 & More than 5 \\
\hline Assault & 98 & 99 & - \\
Robbery & 94 & 99 & 1 \\
Product Fraud & 85 & 93 & 4 \\
Quality Fraud & 21 & 40 & 41 \\
\hline
\end{tabular}

\section{Buyers' response to cheating}

Those buyers who had suffered a type of cheating were invited to briefly state how they responded to the incident. This was an open question where buyers explained their response in their own words. Responses were summarised into broad categories based on a common theme.

Although buyers provided a range of different responses to having been cheated, two responses 'did nothing' and 'changed supplier', emerged as popular responses for nearly all the types of cheating. 
In the case of quality fraud, 31 per cent of victims responded by changing supplier, 29 per cent did nothing, 20 per cent complained to the seller, and 12 per cent asked for replacement drugs or their money back. Only 3 per cent of the victims of quality fraud responded by attacking the dealer.

In the case of product fraud, 28 per cent responded by 'doing nothing', 22 per cent changed their supplier, 16 per cent complained to the seller, and 14 per cent asked for replacement drugs or their money back. Seven percent responded by attacking the dealer.

In the case of robbery, 39 per cent responded by 'doing nothing', 27 per cent changed suppliers, 15 per cent attacked the dealer, and seven per cent warned other buyers about the seller.

Finally, in the case of the 10 buyers who had been assaulted, six responded by 'fighting back', three did nothing, and one reported the incident to the police.

\section{Perceptions of the safety and reliability of the cannabis market}

Buyers were asked directly how safe and reliable they considered cannabis transactions to be relative to legal transactions. They were provided with five statements about the reliability of cannabis transactions from which they were asked to choose one: 'Very unsafe and unreliable'; 'Pretty unsafe and unreliable'; 'Slightly less safe and reliable than legal transactions'; 'About the same as legal transactions'; and 'More safe and reliable than legal transactions'.

Fourteen percent of buyers considered cannabis transactions to be 'More safe and reliable than legal transactions', 30 per cent thought cannabis transactions were 'About the same' as legal transactions, 37 per cent thought cannabis transactions were 'Slightly less safe and reliable' than legal transactions, 13 per cent thought cannabis transactions were 'Pretty unsafe and unreliable', and six per cent thought cannabis transactions were 'Very unsafe and unreliable'.

Most buyers (67 per cent) thought cannabis transactions were 'about the same', or only 'slightly less safe and reliable', than legal transactions. The 14 per cent of buyers who reported they considered their cannabis transactions to be 'More safe and reliable than legal transactions' may have had exceptionally secure exchange relationships, such as purchasing from a trusted friend or family member.

\section{Discussion}

This paper has investigated the reliability of illicit cannabis transactions in New Zealand. The simple economic model developed suggested when exchange is ongoing between the same two exchange partners, and the search costs of finding an alternative exchange partner are high, it will often be rational to honour the terms of illicit cannabis transactions even when there is no third party enforcement of transactions. Search costs are high in illicit drug markets because exchange parties are secretive and suspicious, there are no market institutions to assist 
exchange parties with finding exchange partners, and market search can result in arrest or public embarrassment.

Note, the scope of the model is restricted to the incentives faced by exchange parties only, it does not investigate any incentives third parties might have to victimise exchange parties. Drug dealers and drug users are apparently attractive targets for robbery by the general criminal fraternity as they are known to carry large quantities of cash and drugs and often carry out transactions in secluded areas away from the view of the police and public (Barnett, 1987).

The ALCP survey found incidents of assault, robbery, and product fraud while purchasing cannabis from the black market were rare. In contrast, quality fraud was found to be fairly common. The selectivity of the ALCP sample means the data collected cannot be used to provide a representative picture of the cannabis black market in New Zealand. However, given the difficulties in gaining access to a representative sample of people who purchase cannabis, and the absence of any data on the reliability of the black market to date, the results of the ALCP survey provide valuable information on the reliability of cannabis transactions in New Zealand.

The ALCP sample contained a large number of experienced cannabis buyers who may well have more established, and therefore more reliable and peaceful, sources of supply than less experienced consumers. A research question that emerges from the ALCP survey, which cannot be answered with the data collected here is, are there subgroups of cannabis buyers, for example inexperienced buyers, young people, or women, who are more likely to be victimised while purchasing cannabis from the black market.

One explanation for the high levels of quality fraud experienced in the black market is that quality fraud is not sufficiently costly to cause buyers to go elsewhere for cannabis (Wilkins, 1999). Cannabis sellers are therefore aware they can 'get away' with this type of cheating without their customer going elsewhere. The difficulties in finding cannabis sellers may mean buyers will only quit an existing seller when the costs of cheating are large enough to justify the time and effort involved in finding a new seller.

An alternative explanation for the high levels of quality fraud relates to the lack of an objective measure of the quality of cannabis in the black market (Wilkins, 1999). The absence of product packaging and product labelling in black markets means there is no accessible objective measure of cannabis quality. Inflated black market prices may encourage a general feeling amongst buyers of not receiving value for money. Buyers may therefore feel they have been victims of quality fraud even when no fraud was intended.

\section{Conclusion}

Several groups in New Zealand have suggested the legalisation of cannabis is required to protect those who buy and sell the drug on the black market from economic and physical victimisation. The ALCP survey suggests cannabis transactions in New Zealand are generally peaceful and reliable. Cannabis 
prohibition does not appear to place those who purchase the drug from the black market in any extreme physical danger. The principal risk of victimisation appears to be economic. Cannabis buyers are occasionally sold a fraudulent product, and believe they regularly receive a lower quality product than they pay for.

The extent of the social benefits gained from a legal and regulated cannabis market, in terms of improving the reliability of cannabis transactions, may therefore be fairly limited. Those in favour of limiting the use of illicit drugs might consider the economic victimisation experienced by cannabis buyers and sellers to be a justified harm for those who persist in using illegal substances, and who support and earn profit from the criminal trade in drugs.

From a broader policy perspective a number of questions can be raised about the extent to which legalisation and regulation of the cannabis market would actually reduce victimisation and violence in society. A number of policy commentators have pointed out that even if drugs were legalised, a significant black market may continue to persist if the taxation and regulation of the market were too strict (Kleiman and Saiger, 1990; Jacobs, 1990).

This would appear to be a particular risk in the case of cannabis because of the ease with which the plant can be cultivated and the widespread nature of the existing black market. For many drug consumers the transaction costs of participating in the legal market will exceed the transaction costs of continuing to transact in the illegal market (Wilkins and Scrimgeour, 2000). If a significant cannabis black market persisted after legalisation any victimisation and violence related to the black market would presumably continue.

Alternatively, if the cannabis black market were significantly reduced by the legalisation of the drug violent criminals involved in the cannabis trade may simply switch to involvement in, and expansion of, other illicit drug markets, such as the heroin or methamphetamine trade, or for that matter any number of other criminal activities. Goldstein (1997) believes much of the systematic violence related to illicit drug markets is 'face-saving' violence committed by naturally aggressive individuals. The violence and victimisation associated with the cannabis black market may therefore simply shift to other criminal activities rather than be greatly reduced or eliminated.

An anonymous referee made the point that it is not entirely clear that a legal cannabis market would completely eliminate the quality cheating found in the illicit market. The work of Barzel (1989) has shown that even in legal markets property rights are never perfectly specified or perfectly enforced, and consequently valuable attributes of products are left in the common pool to be captured by opportunistic exchange parties. The level of cheating in the illicit market should therefore be compared with the level of cheating that would persist in a legal market.

Of course the future of cannabis policy in New Zealand will not be decided by the reliability of black market cannabis transactions alone. The impact any law change might have on the prevalence of cannabis use, and the cost of the enforcement regime, are still likely to be the most influential factors in the 
selection of a cannabis control policy (see Field and Casswell, 2000). There is a real concern about the extent the legalisation of cannabis would contribute to an increase in the use of the drug, and the extent increased use would contribute to greater cannabis related health and social problems (see, for example, Kleiman 1989 and 1992; Wilson, 1990; Inciardi and Saum, 1996). The issue examined here is just one amongst many that emerges from the evaluation of cannabis policy options and the results and discussion in this paper should be viewed in this wider policy context.

\section{References}

Axelrod, R. (1981), 'The Evolution of Co-operation Among Egoists', American Political Science Review 75:306-318.

Axelrod, R. (1990), The Evolution of Co-operation, Penguin Books, London.

Barnett, R. (1987), 'Curing the Drug-Law Addiction: The Harmful Side Effects of Legal Prohibition', pp. 73-102 in R. Hamowy (ed.), Dealing with Drugs: Consequences of Government Control, Lexington Books, Lexington, Mass.

Barzel, Y. (1989), 'Economic Analysis of Property Rights, Cambridge University Press, Cambridge.

Coase, R. (1960), 'The Problem of Social Cost', Journal of Law and Economics 3:1-44.

Coase, R. (1988), The Firm, the Market, and the Law, University of Chicago Press, Chicago.

Demsetz, H. (1964), 'The Exchange and Enforcement of Property Rights', Journal of Law and Economics 7:11-26.

Drug Policy Forum Trust (1997), Alternative Systems of Cannabis Control in New Zealand: A Discussion Paper, Wellington.

Drug Policy Forum Trust (1998), New Zealand Should Regulate and Tax Cannabis Commerce: Final Report, Wellington.

Eggertsson, T. (1990), Economic Behaviour and Institutions, Cambridge University Press, Cambridge.

Field, A, and S. Casswell (2000), 'Options for Cannabis Policy in New Zealand', Social Policy Journal of New Zealand 14:49-64.

Goldstein, P. (1997), 'The Relationship Between Drugs and Violence in the United States of America', pp. 116-121 in World Drug Report (United Nations International Drug Control Programme), Oxford University Press, Oxford.

Goldstein, P., H. Brownstein, P. Ryan and P. Bellucci (1989), 'Crack and Homicide in New York City, 1988: A Conceptually Based Event Analysis', Contemporary Drug Problems 16(4):651-687.

Inciardi, J. and C. Saum (1996), 'Legalisation Madness', Public Interest 123:72-82. 
Jacobs, J. (1990), 'Imagining Drug Legalisation', Public Interest 101:28-42.

Kleiman, M, (1989), Marijuana: Costs of Abuse, Costs of Control, Greenwood Press, New York.

Kleiman, M. (1992), Against Excess: Drug Policy for Results, Basic Books, New York.

Kleiman, M. and A. Saiger (1990), 'Drug Legalisation: The Importance of Asking the Right Question’, Hofstra Law Review 18:527-565.

Long, H. (1988), Getting Started in the Illicit Drug Business, Loompanics Unlimited, Cambridge.

Michaels, R. (1987), ‘The Market for Heroin Before and After Legalisation', pp. 289-325 in R. Hamowy (ed.), Dealing with Drugs: Consequences of Government Control, Lexington Books, Lexington.

Miron, J. and J. Zwiebel (1995), 'The Economic Case Against Drug Prohibition', Journal of Economic Perspectives 9(4):175-192.

Moore, M. (1977), Buy and Bust, D.C. Heath, Lexington.

National Drugs Intelligence Bureau (2000), Cannabis in New Zealand 2000, Government Printer, Wellington.

North, D. (1990), Institutions, Institutional Change, and Economic Performance, Cambridge University Press, Cambridge.

Reuter, P. and J. Haaga (1989), The Organisation of High Level Drug Markets, MIT Press, Cambridge, Mass.

Reuter, P, R. MacCoun and P. Murphy (1990), Money from Crime: A Study of the Economics of Drug Dealing in Washington DC, RAND Corporation, Santa Monica, CA.

Wilkins, C. (1999), Cheating in Retail Illicit Drug Transactions: Theory and Evidence, Doctoral Thesis, University of Waikato, Hamilton

Wilkins, C. and F. Scrimgeour (2000), 'Economics and the Legalisation of Drugs', Agenda 7(4):333-345.

Wilson, J. (1990), 'Against the Legalisation of Drugs', Commentary 89(2):21-28.

The author would like to thank Franco Papandrea for suggestions on an earlier draft, and two anonymous referees for comments. The research presented in this paper was carried out at the Economics Department, University of Waikato, and written up at the Alcohol \& Public Health Research Unit, University of Auckland. The views expressed in this article are those of the author and are not necessarily shared by the University of Waikato or the Alcohol \& Public Health Research Unit. 